\title{
PENGARUH BAURAN KOMUNIKASI PEMASARAN TERHADAP KEPUTUSAN PEMBELIAN SEPEDA MOTOR MEREK HONDA DI PEKANBARU
}

\author{
Yusriadi \\ Sekolah Tinggi Ilmu Ekonomi Riau \\ Jln. HR Subrantas KM 12 Panam Pekanbaru \\ E-mail : yusriadi76@gmail.com \\ diterima: 4/9/2018; direvisi: 29/9/2018; diterbitkan: 31/3/2019
}

\begin{abstract}
This study aims to determine the effect of variable marketing communication mix including advertising, personal selling, sales promotion, public relations and direct marketing on Honda motorbike brand purchase decisions both partially and simultaneously with 84 respondents using insidential sampling methods. From the results of data analysis using multiple regression, the results of the test obtained the results of variable advertising, personal selling and sales promotion had no effect and not significant to the purchase decision of Honda brand motorcycles. While public relations and direct marketing variables influence the purchase decision of Honda brand motorcycles. While the results of the F test have an effect on and significant means advertising, personal selling, sales promotion, public relations and direct marketing simultaneously affect the purchase decision of Honda brand motorcycles.
\end{abstract}

Keywords: advertising, personal selling, sales promotion, public relations, direct marketing and purchase decision

\section{PENDAHULUAN}

Pertumbuhan pasar otomotif di Indonesia dari tahun ke tahun menunjukkan perkembangan yang sangat baik, berbagai macam produk kendaraan yang di tawarkan kepada masyarakat selalu mendapatkan respon yang positif. Dari sejumlah produk otomotif yang ada di Indonesia, kendaraan bermotor roda dua atau yang sering disebut sepeda motor merupakan produk otomotif yang paling diminati di Indonesia. Hal ini dikarenakan sepeda motor sangat fleksibel dan efisien untuk menunjang mobilitas masyarakat seharihari. Oleh karena itu, sepeda motor menjadi pangsa pasar yang sangat potensial dalam dunia bisnis otomotif di Indonesia.

Dalam pemberitaan di website tribunnews pada tanggal 18 Juli 2018 di beritakan bahwa sepeda motor nasional mencatatkan trend positif pada semester I-2018. Pelaku industri pun optimis penjualannya akan tetap melesat naik di semester II-2018. Dari data Asosiasi Sepeda Motor Indonesia (AISI), tercatat penjualan Januari hingga Juni 2018 mencapai 3.002.753 unit atau naik $11,1 \%$ dari periode sama tahun lalu sebesar 2.700.546 unit. General Manager Sales Division PT Astra Honda Motor (AHM), Ignatius Didi Kwok mengatakan bahwa "trend penjualan AHM di semester I-2018 ini akan minimal sama seperti semester I2018, sehinggga total penjualan di tahun ini bisa mencapai 4,4 juta unit sampai dengan 4,6 juta”.

Berikut ini data penjualan sepeda motor dengan 4 merek ternama yakni Honda, Yamaha, Suzuki dan Kawasaki di Indonesia yang di lansir oleh http://triatmono.info/ pada tahun 2017. Dari data di atas menunjukkan sepeda motor merek Honda mendominasi dengan total penjualan di angka 4.385.888 unit di susul Yamaha dengan penjualan 1.348.563 unit, selanjutnya Kawasaki di angka 78.637 unit dan yang paling bawah pada merek Suzuki di angka 72.191 unit. 
Jurnal Ilmiah Ekonomi dan Bisnis

Vol. 16. No.1, Maret 2019: 1-9

EISSN : $2442-9813$

ISSN : : $1829-9822$

Secara persentase Honda menguasai secara telak penjualan sepeda motor di tahun 2017 pada angka 74,5\%.

Tabel 1: penjualan sepeda motor dengan 4 merek ternama yakni Honda, Yamaha, Suzuki dan Kawasaki di Indonesia

\begin{tabular}{|l|r|r|r|r|}
\hline Periode & \multicolumn{1}{c|}{ Honda } & Yamaha & Suzuki & Kawasaki \\
\hline Januari & 368.739 & 94.117 & 3.511 & 7.370 \\
\hline Pebruari & 345.921 & 93.511 & 5.904 & 8.298 \\
\hline Maret & 358.524 & 98.040 & 8.600 & 8.601 \\
\hline April & 274.155 & 101.908 & 5.879 & 6.002 \\
\hline Mei & 394.751 & 122.186 & 8.526 & 5.915 \\
\hline Juni & 263.854 & 105.133 & 6.270 & 4.143 \\
\hline Juli & 403.487 & 120.608 & 7.312 & 6.690 \\
\hline Agustus & 418.931 & 123.972 & 6.279 & 6.009 \\
\hline Sepetember & 408.116 & 124.360 & 6.823 & 7.224 \\
\hline Oktober & 436.974 & 129.636 & 6.172 & 6.658 \\
\hline Nopember & 430.487 & 109.834 & 3.617 & 6.274 \\
\hline Desember & 281.949 & 125.258 & 3.298 & 5.453 \\
\hline \multicolumn{1}{|c|}{ Total } & $\mathbf{4 . 3 8 5 . 8 8 8}$ & $\mathbf{1 . 3 4 8 . 5 6 3}$ & $\mathbf{7 2 . 1 9 1}$ & $\mathbf{7 8 . 6 3 7}$ \\
\hline
\end{tabular}

Tumbuhnya pasar otomotif di Indonesia dan meningkatnya penjualan sepeda motor secara signifikan tidak terlepas dari aktivitas promosi yang di lakukan oleh pihak perusahaan. Promosi yang baik tentunya akan berpengaruh terhadap peningkatan penjualan. Sebagaimana dari berbagai refrensi di sebutkan bahwa promosi adalah aktivitas pemasaran dalam menginformasikan dan mempengaruhi orang atau pihak lain sehingga tertarik untuk melakukan transaksi atau pertukaran produk barang atau jasa yang dipasarkannya.

Promosi memiliki beberapa tujuan, yakni untuk menyebarkan informasi produk kepada target pasar potensial, mendapatkan kenaikan penjualan dan profit, mendapatkan pelanggan baru dan menjaga kesetiaan pelanggan, menjaga kestabilan penjualan ketika terjadi kelesuan pasar, membedakan dan mengunggulkan produk dibandingkan dengan produk pesaing, serta membentuk citra produk di mata konsumen sesuai dengan yang diinginkan.

Konsep promosi yang digunakan perusahaan menggunakan strategi bauran komunikasi pemasaran yang merupakan gabungan dari berbagai jenis promosi yang ada untuk suatu produk yang sama agar hasil dari kegiatan promosi yang dilakukan dapat memberikan hasil yang maksimal yakni mencakup advertising, personal selling, sales promotion, public relation dan direct marketing.

Berdasarkan latar belakang yang telah dikemukakan di atas, maka rumusan masalah dalam penelitian ini adalah : "Apakah bauran komunikasi pemasaran yang variabelnya adalah advertising, personal selling, sales promotion, public relation dan direct marketing berpengaruh dan signifikan terhadap keputusan pembelian sepeda motor merek Honda di Kota Pekanbaru baik secara parsial maupun simultan?

Adapun tujuan penelitian ini adalah untuk mengetahui pengaruh apakah bauran komunikasi pemasaran yang variabelnya adalah advertising, personal selling, sales promotion, public relation dan direct marketing berpengaruh dan signifikan terhadap keputusan pembelian sepeda motor merek Honda di Kota Pekanbaru baik secara parsial maupun simultan.

\section{TINJAUAN PUSTAKA}

Pemasaran adalah proses sosial yang didalamnya individu dan kelompok mendapatkan apa yang mereka butuhkan dan inginkan dengan menciptakan, menawarkan dan secara bebas mempertukarkan produk yang bernilai dengan pihak lain. Kotler dalam Danang Sunyoto (2014) menyatakan bahwa pemasaran adalah suatu sistem keseluruhan dari kegiatan-kegiatan bisnis yang ditujukan untuk merencanakan, menentukan harga, mempromosikan dan mendistribusikan barang dan jasa yang memuaskan kebutuhan baik kepada 
pembeli yang ada maupun pembeli potensial.

Menurut Kotler dan Armstrong (2009), pemasaran adalah segala kegiatan untuk menyampaikan barangbarang ke tangan (rumah tangga) dan ke konsumen industri, tetapi tidak termasuk kegiatan perubahan bentuk barang. Pengertian pemasaran dari pendapat di atas menerangkan bahwa kegiatan pemasaran mencakup ruang lingkup kegiatan yang sangat luas yang dimulai dari menetukan kebutuhan konsumen dan diakhiri dengan kepuasan konsumen. Dengan kata lain kegiatan pemasaran bermula dan berakhir pada konsumen.

Menurut Hurriyanti, Ratih (2015) Promosi adalah suatu bentuk komunikasi pemasaran yang merupakan aktivitas pemasaran yang berusaha menyebarkan informasi, mempengaruhi atau membujuk, dan atau mengingatkan pasar sasaran atas perusahaan dan produk agar bersedia menerima, membeli, dan loyal pada produk yang ditawarkan perusahaan yang bersangkutan.

Menurut Buchari Alman dikutip dalam buku Fandy Tjiptono (2015) promosi merupakan salah satu faktor penentu keberhasilan suatu program pemasaran. Betapa pun berkualitasnya sebuah produk, bila konsumen belum pernah mendengarnya dan tidak yakin bahwa produk itu akan berguna bagi mereka, maka mereka tidak membelinya.

Menurut Hurriyanti, Ratih (2015) Tujuan dari promosi adalah memberikan informasi, membujuk dan mempengaruhi, menciptakan kesan, memuaskan keinginan dan sebagai alat komunikasi. 1) Memberikan Informasi, Para ahli ekonomi telah menekankan adanya faedah kegunaan waktu, tempat, bentuk, dan milik dalam pemasaran, sebuah barang akan lebih berharga bagi seseorang apabila ia dapat memperolehnya setiap waktu, pada setiap tempat dan memilikinya dengan mudah, sebenarnya masih ada satu faedah lagi yang tidak kalah penting dengan faedah-faedah lainnya, yakni faedah informasi (informasi utility). Jadi periklanan dapat menambah nilai pada suatu barang dengan memberikan informasi kepada konsumen. 2) Membujuk dan Mempengaruhi, Sering periklanan tidak hanya memberitahukan saja, tetapi juga memberikan sifat membujuk terutama kepada pembelipembeli pontensial, dengan menyatakan bahwa suatu produk adalah lebih baik dari pada produk yang lain. 3) Menciptakan Kesan (image), Dengan sebuah iklan, orang akan mempunyai suatu kesan tertentu tentang apa yang diiklankannya. Dalam hal ini pemasang iklan selalu berusaha untuk menciptakan iklan yang sebaik-baiknya, misal dengan menggunakan warna, ilustrasi, bentuk dan susunan yang menarik. 4) Memuaskan Keinginan, Sebelum memilih dan membeli produk, kadang-kadang orang ingin diberitahu lebih dahulu. Sebagai contoh mereka ingin mengetahui lebih dulu tentang gizi, vitamin, dan harga pada produk makanan yang paling baik untuk keluarga, jadi periklanan merupakan suatu alat yang dapat dipakai untuk mencapai tujuan, dan tujuan itu sendiri berupa pertukaran yang saling memuaskan. 5) Sebagai alat Komunikasi, Periklanan adalah suatu alat untuk membuka komunikasi dua arah antara penjual dan pembeli, sehingga keinginan mereka dapat terpenuhi dengan cara efektif dan efesien.

Menurut (Kotler dan Armstrong, 2008) ada aneka macam melakukan promosi dan kencenderungannya ialah cara yang dipakai makin berkembang. Secara baris besar jenis-jenis kegiatan promosi dapat di uraikan sebagai berikut: 1) Advertising (Periklanan), Periklanan dipandang sebagai kegiatan penawaran kepada suatu kelompok masyarakat baik secara langsung lisan maupun dengan penglihatan (berupa berita) tentang suatu 


\section{Jurnal Ilmiah Ekonomi dan Bisnis}

Vol. 16. No.1, Maret 2019: 1-9

EISSN : $2442-9813$

ISSN : $1829-9822$

produk, jasa atau ide. Tetapi periklanan dilakukan engan mengeluarkan sejumlah biaya, berbeda dengan publisitas yang disiarkan tanpa melakukan biaya. Kegiatan periklanan berarti kegiatan menyebarluaskan berita (informasi) kepada pasar (masyarakat/konsumen). 2) Personal selling (penjualan pribadi), Personal selling atau penjulan peribadi disini adalah merupakan komunikasi persuasif seseorang secara individual kepada seseorang atau lebih calon pembeli dengan maksud menimbulkan permintaan (penjualan). Lain halnya dengan periklanan dan kegitan promosi lainnya yang komunikasi bersifat non pribadi atau masal. 3) Public Relation (hubungan masyarakat), Sejumlah informasi tentang seseorang, barang atau organisasi/ perusahaan yang disebar luaskan kemasyarakat dengan cara membuat berita yang mempunyai arti komersial atau berupa penyajianpenyajian yang lain yang bersifat positif. Dengan demikian suatu perusahaan beserta produknya dapat menjadi perhatian umum. 4) Sales promotion (Promosi Penjualan), Alat kegiatan promosi selain periklanan, personal selling dan publisitas ialah merupakan sales promotion yang dilakukan dengan peragaan, pertunjukan dan pameran, demostrasi dan berbagai macam usaha penjualan yang bersifat tidak rutin. Ada beberapa macam metode sales promotion yang ditunjukan kepada konsumen seperti: pemberian contoh barang, kupon/nota, hadiah, kupon berhadiah, undian, rabat dan peragaan. 5) Direct marketing (pemasaran langsung) adalah hubungan langsung dengan konsumen individual yang ditargetkan secara cermat untuk memperoleh respons langsung dan membangun hubungan pelanggan yang langgeng penggunaan surat langsung, telepon, televisi respons langsung, $e$ mail, Internet, dan sarana lain untuk berkomunikasi secara langsung dengan konsumen tertentu.

Schiffman dan Kanuk dikutip dalam buku Sudaryono (2016) menggambarkan pada saat mengambil keputusan, semua pertimbangan ini akan dialami oleh konsumen walaupun perannya akan berbeda-beda disetiap individu. Proses pengambilan keputusan diawali oleh adanya kebutuhan yang berusaha untuk dipenuhi. Keputusan pembelian akan dilakukan dengan menggunakan kaidah menyeimbangkan sisi positif dan sisi negatif suatu merek atau pun mencari solusi terbaik dari perspektif konsumen yang setelah dikonsumsi akan dievaluasi kembali.

Menurut Sudaryono (2016) dalam pemenuhan kebutuan hidupnya, seorang konsumen harus memilih produk dan jasa yang akan dikonsumsinya. Banyaknya pilihan yang tersedia, kondisi yang dihadapi, serta pertimbanganpertimbangan yang mendasari dalam kemudian membuat pengambilan keputusan satu individu berbeda dengan individu lain.

Hipotesis dalam penelitian ini adalah bauran komunikasi pemasaran yang variabelnya advertising, personal selling, public relation, sales promotion dan direct marketing di duga berpengaruh secara signifikan baik secara parsial maupun simultan terhadap keputusan pembelian sepeda motor merek Honda di Pekanbaru.

\section{METODE PENELITIAN}

Desain dalam penelitian ini merupakan penelitian deskriptif dan asosiatif (hubungan/pengaruh) yang bertujuan untuk mengetahui nilai masingmasing variable, baik satu atau lebih sifatnya independen tanpa membuat hubungan maupun perbandingan dengan variabel yang lain. Desain penelitian asosiatif adalah penelitian yang di desain untuk mengetahui pengaruh interaksi antara dua variabel atau lebih. 
Populasi menurut Sugiono (2009) adalah wilayah generalisasi yang terdiri atas obyek/subyek yang mempunyai kualitas dan karakteristik tertentu yang ditetapkan oleh peneliti untuk dipelajari dan kemudian ditarik kesimpulannya. Populasi dalam penelitian ini adalah konsumen yang sudah membeli sepeda motor merek honda dikota Pekanbaru. Pengambilan sampel nya melalui metode sampling insidential yakni teknik penentuan sampel secara kebetulan, atau siapa saja yang kebetulan (insidential) bertemu dengan peneliti yang dianggap cocok dengan karakteristik sampel yang ditentukan akan dijadikan sampel dengan jumlah 84 orang. Menurut Roscoe dan Uma Sekaran dalam Wiratna Sujarweni (2015) memberikan acuan umum untuk menentukan jumlah sampel minimal 30 dan kurang dari 500 sudah tepat untuk dilakukan suatu penelitian.

Jenis dan sumber data yang digunakan dalam penelitian ini adalah sebagai berikut data kualitatif, yaitu data yang diperoleh dalam bentuk informasi, baik secara lisan maupun tulisan yang berkaitan dengan masalah yang diteliti. Data Kuantitatif, yaitu data yang diperoleh dalam bentuk angka-angka yang dapat dihitung, yang berkaitan dengan masalah yang diteliti. Dalam usaha memperoleh data yang dibutuhkan, metode yang digunakan adalah Studi kepustakaan (Library Research) yaitu yang dilakukan dengan membaca buku-buku dan majalah yang berhubungan dengan masalah yang diteliti, skripsi maupun thesis sebagai acuan penelitian terdahulu, dan dengan cara browsing di internet untuk mencari artikel-artikel serta jurnal-jurnal atau data-data yang dapat membantu hasil dari penelitian.

Dalam metode analisis data ini menggunakan analisis regresi linear sederhana dengan spesifikasi model sebagai berikut : $\mathrm{Y}=\mathrm{a}+\mathrm{bX}+\mathrm{e}$ $Y=a+b_{1} X_{1}+b_{2} X_{2}+b_{3} X_{3} b_{4} X+b_{5} X_{5}+e$
Keterangan :

ISSN : $1829-9822$

$\begin{array}{ll}\mathrm{Y} & : \text { Keputusan Pembelian } \\ a & : \text { Konstanta } \\ \mathrm{X}_{1} & : \text { Advertising } \\ \mathrm{X}_{2} & : \text { Personal Selling } \\ \mathrm{X}_{3} & : \text { Sales Promotion } \\ \mathrm{X}_{4} & : \text { Public Relation } \\ \mathrm{X}_{5} & : \text { Direct Marketing } \\ b & : \text { Koefisien regresi } \\ e & : \text { Variabel pengganggu }\end{array}$

\section{HASIL DAN PEMBAHASAN}

Pertanyaan apakah iklan melalui media cetak berupa baleho, spanduk, brosur, banner dll, maupun iklan melalui media elektronik mempengaruhi responden untuk memutuskan pembelian sepeda motor merek honda. Dari data diatas menunjukkan bahwa iklan (advertising) masih sangat efektif dalam mempengaruhi responden untuk memutuskan pembelian sepeda motor merek honda dengan tingkat persentase sangat setuju 26,2 \% dan setuju 59,5\%.

Pertanyaan apakah penawaran secara pribadi (personal selling) dari para Marketer mempengaruhi responden untuk memutuskan pembelian sepeda motor merek honda. Dari data diatas menunjukkan bahwa pendekatan secara pribadi atau (personal selling) masih sangat efektif dalam mempengaruhi responden untuk memutuskan pembelian sepeda motor merek honda dengan tingkat persentase sangat setuju $11,9 \%$ dan setuju $56 \%$.

Pertanyaan apakah responden memutuskan pembelian sepeda motor merek honda karena adanya discount atau kemudahan lain dari sisi pembayaran (sales promotion) bahwa sales promotion melalui discount dan kemudahan pembayaran masih sangat efektif dalam mempengaruhi responden untuk memutuskan pembelian sepeda motor merek honda dengan tingkat persentase sangat setuju $29,8 \%$ dan setuju $44 \%$. 
Jurnal Ilmiah Ekonomi dan Bisnis

Vol. 16. No.1, Maret 2019: 1-9

EISSN : $2442-9813$

ISSN : $1829-9822$

Pertanyaan apakah penilaian yang baik oleh masyarakat tentang sepeda motor merek honda mempengaruhi responden memutuskan untuk melakukan pembelian sepeda motor merek honda. Dari data diatas menunjukkan bahwa public relation dimana sepeda motor merek honda mampu membangun opini yang positif di tengah masyarakat sehingga mampu mempengaruhi responden dalam memutuskan pembelian sepeda motor mereka honda dengan tingkat persentase sangat setuju 45,2 \% dan setuju $50 \%$.

Pertanyaan apakah responden memutuskan pembelian sepeda motor merek honda karena mendapatkan penawaran secara langsung melaui surat, email, sms atau BC dari WA, BBM, Line, Twitter, FB dan IG. Dari data diatas menunjukkan bahwa direct marketing atau penawaran langsung melalui surat, email, sms atau BC dari WA, BBM, Line, Twitter, FB dan IG tidak efektif dalam mempengaruhi responden untuk memutuskan pembelian sepeda motor merek honda dengan tingkat persentase yang menjawab setuju hanya $23 \%$ dan lebih besar yang mejawab biasa saja 48,8\%.

Pernyataan

responden

memutuskan sendiri tanpa ada masukan dari orang lain dalam memilih sepeda motor merek honda. Dari data diatas menunjukkan bahwa keputusan responden dalam memutuskan pembelian sepeda motor merek honda di pengaruhi atas pengetahuan sendiri cukup besar dengan tingkat persentase sangat setuju $17,9 \%$ dan setuju $57,1 \%$.

Pernyataan ada faktor pengaruh atau masukan dari orang lain yang menyebabkan responden memutuskan pembelian sepeda motor merek honda. Dari data diatas menunjukkan bahwa keputusan responden dalam memutuskan pembelian sepeda motor merek honda di pengaruhi oleh orang lain juga cukup besar dengan tingkat persentase sangat setuju $10,7 \%$ dan setuju 53,6\%.

Berikut ini data rekapitulasi hasil analisis deskriptif di urut berdasarkan persentase tertinggi apabila jawaban responden untuk yang menjawab sangat setuju dan setuju digabung menjadi satu.

Dari data diatas menunjukkan bahwa secara urutan dari persentase terbesar sampai yang terkecil keputusan pembelian sepeda motor merek honda yang tertinggi karena honda di nilai masyarakat masih yang terbaik (public relation) dengan angka 95,2\%. Berikutnya di urutan kedua faktor iklan (advertising) di media cetak maupun elektronik sebesar 85,7\%. Di urutan ketiga karena faktor discount dan kemudahan dari sisi pembayaran (sales promotion) sebesar $73,8 \%$. Berikutnya di posisi keempat untuk faktor pendekatan dari marketer (personal selling) sebesar $67,9 \%$. Sedangkan urutan terakhir melalui penjualan langsung (direct marketing) hanya sebesar $29,8 \%$.

Uji normalitas dilakukan untuk mengetahui apakah data yang diambil dalam penelitian berasal dari populasi yang berdistribusi normal atau tidak. Model regresi yang baik adalah yang datanya berdistribusi normal. Dengan menggunakan SPSS 20. Uji normalitas dengan normal probability plot mensyaratkan bahwa penyebaran data harus berada disekitar wilayah garis diagonal dan mengikuti arah garis diagonal. Berdasarkan gambar di atas dapat disimpulkan bahwa data dalam penelitian ini memenuhi syarat normal probability plot sehingga model regresi dalam penelitian memenuhi asumsi normalitas/ berdistribusi normal).

Hasil pengolahan analisis regresi sederhana dengan menggunakan software SPSS 20 adalah sebagai berikut : 
Tabel 2: Coefisien regresi

Coefficients ${ }^{\text {a }}$

\begin{tabular}{|c|c|c|c|c|c|c|}
\hline \multirow{2}{*}{\multicolumn{2}{|c|}{ Model }} & \multicolumn{2}{|c|}{ Unstandardized Coefficients } & \multirow{2}{*}{$\begin{array}{c}\begin{array}{c}\text { Standardized } \\
\text { Coefficients }\end{array} \\
\text { Beta }\end{array}$} & \multirow[b]{2}{*}{$t$} & \multirow[b]{2}{*}{ Sig. } \\
\hline & & B & Std. Error & & & \\
\hline \multirow[t]{6}{*}{1} & (Constant) & 3,196 & .913 & & 3,501 &, 001 \\
\hline & Advertising & - 029 & .227 &,- 015 & -128 & .898 \\
\hline & Personal_Selling & 194 & , 196 &, 113 &, 986 &, 327 \\
\hline & Sales_Promotion & - 161 & 176 & - 106 & -.916 &, 362 \\
\hline & Public_Relation & .475 & 209 & .270 & 2,278 & .025 \\
\hline & Direct_Marketing & .681 & 154 & .474 & 4,414 & .000 \\
\hline
\end{tabular}

Untuk mengetahui variabel yang berpengaruh signifikan secara parsial dilakukan pengujian koefisien regresi dengan menggunakan statistik Uji t. Penentuan hasil pengujian (penerimaan/ penolakan $\mathrm{H}_{0}$ ) dapat dilakukan dengan membandingkan t-hitung dengan t-tabel atau juga dapat dilihat dari nilai signifikansinya. Adapun nilai t tabel dari penelitian ini adalah dengan tingkat signifikansi $5 \%$, adalah nilai df sebesar $(\mathrm{n}-\mathrm{k})$, dimana $\mathrm{n}=$ jumlah sampel dan $\mathrm{k}$ $=$ jumlah variabel, maka hasilnya $(84-6$ $=78$ ). Dalam t tabel angka 78 dengan tingkat signifikansi 0.05 adalah sebesar 1,664. Berikut hasil tabel uji $t$ berdasarkan pengolahan data SPSS 21 .

Pengaruh Advertising terhadap keputusan Pembelian Sepeda Motor Merek Honda

Berdasarkan tabel 2 terlihat pada kolom Coefficients model 1 terdapat nilai sig 0,898 . Nilai sig lebih besar dari nilai probabilitas 0,05 , atau nilai $0,000>$ 0,05, maka $\mathrm{H}_{1}$ ditolak dan Ho diterima. Variabel $\mathrm{X}_{1}$ mempunyai $\mathrm{t}_{\text {hitung }}-0,128$ sedangkan $t_{\text {tabel }} 1,664$. Jadi $t_{\text {hitung }}<t_{\text {tabel }}$ dapat disimpulkan bahwa variabel $\mathrm{X}_{1}$ tidak memiliki kontribusi terhadap Y. Nilai $t$ negatif menunjukkan bahwa variabel $\mathrm{X}_{1}$ mempunyai hubungan yang tidak searah dengan $Y$. Jadi dapat disimpulkan bahwa adverstising tidak berpengaruh dan tidak signifikan terhadap Keputusan pembelian sepeda motor merek honda.
Pengaruh Personal Selling terhadap keputusan Pembelian Sepeda Motor Merek Honda

Berdasarkan tabel 11 Terlihat pada kolom Coefficients model 1 terdapat nilai sig 0,327. Nilai sig lebih besar dari nilai probabilitas 0,05, atau nilai 0,327 >0,05, maka $\mathrm{H}_{2}$ ditolak dan $\mathrm{Ho}$ diterima. Variabel $\mathrm{X}_{2}$ mempunyai $t_{\text {hitung }} 0,986$ dengan $t_{\text {tabel }} 1$ 1,664. Jadi $t_{\text {hitung }}<t_{\text {tabel }}$ dapat disimpulkan bahwa variabel $\mathrm{X}_{2}$ memiliki tidak memiliki kontribusi terhadap $\mathrm{Y}$. Nilai $t$ lebih kecil dari $t$ tabel menunjukkan $\mathrm{X}_{2}$ tiak mempunyai pengaruh terhadap variabel Y. Jadi dapat disimpulkan bahwa variabel personal selling tidak berpengaruh secara signifikan terhadap keputusan pembelian sepeda motor merek honda.

Pengaruh sales promotion terhadap keputusan Pembelian Sepeda Motor Merek Honda

Berdasarkan tabel 2 terlihat pada kolom Coefficients model 1 terdapat nilai sig 0,362. Nilai sig lebih besar dari nilai probabilitas 0,05, atau nilai $0,000>0,05$, maka $\mathrm{H}_{3}$ ditolak dan Ho diterima. Variabel $\mathrm{X}_{3}$ mempunyai $\mathrm{t}_{\text {hitung }}-0,916$ sedangkan $t_{\text {tabel }}$ 1,664. Jadi $t_{\text {hitung }}<t_{\text {tabel }}$ dapat disimpulkan bahwa variabel $\mathrm{X}_{3}$ tidak memiliki kontribusi terhadap Y. Nilai $t$ negatif menunjukkan bahwa variabel $\mathrm{X}_{3}$ mempunyai hubungan yang tidak searah dengan Y. Jadi dapat disimpulkan bahwa personal selling tidak berpengaruh dan tidak signifikan terhadap Keputusan pembelian sepeda motor merek honda.

Pengaruh Public Relation terhadap keputusan Pembelian Sepeda Motor Merek Honda. Berdasarkan tabel 11 Terlihat pada kolom Coefficients model 1 terdapat nilai sig 0,025 . Nilai sig lebih kecil dari nilai probabilitas 0,05 , atau nilai $0,025<0,05$, maka $\mathrm{H}_{4}$ diterima dan $\mathrm{Ho}$ ditolak. Variabel $X_{4}$ mempunyai $t_{\text {hitung }}$ 2,278 dengan $t_{\text {tabel }} 1,664$. Jadi $t_{\text {hitung }}>t_{\text {tabel }}$ dapat disimpulkan bahwa variabel $\mathrm{X}_{4}$ 
Jurnal Ilmiah Ekonomi dan Bisnis

Vol. 16. No.1, Maret 2019: 1-9

EISSN : $2442-9813$

ISSN : $1829-9822$

memiliki kontribusi terhadap Y. Nilai $\mathrm{t}$ lebih besar dari t tabel menunjukkan $\mathrm{X}_{4}$ mempunyai pengaruh terhadap variabel Y. Jadi dapat disimpulkan bahwa variabel public relation berpengaruh secara signifikan terhadap keputusan pembelian sepeda motor merek honda.

Pengaruh Direct Marketing terhadap keputusan Pembelian Sepeda Motor Merek Honda

Berdasarkan tabel 2 Terlihat pada kolom Coefficients model 1 terdapat nilai sig 0,00 . Nilai sig lebih kecil dari nilai probabilitas 0,05 , atau nilai $0,00<$ 0,05, maka $\mathrm{H}_{5}$ diterima dan Ho ditolak. Variabel $\mathrm{X}_{5}$ mempunyai $t_{\text {hitung }} 4,414$ dengan $t_{\text {tabel }}$ 1,664. Jadi $t_{\text {hitung }}>t_{\text {tabel }}$ dapat disimpulkan bahwa variabel $\mathrm{X}_{5}$ memiliki kontribusi terhadap Y. Nilai $t$ lebih besar dari t tabel menunjukkan $\mathrm{X}_{5}$ mempunyai pengaruh terhadap variabel Y. Jadi dapat disimpulkan bahwa variabel Direct Marketing berpengaruh secara signifikan terhadap keputusan pembelian sepeda motor merek honda.

Uji statistik $F$ bertujuan untuk mengetahui apakah semua variabel independen yang dimasukkan dalam model mempunyai pengaruh secara bersama-sama terhadap variabel dependennya. Dalam tabel $\mathrm{F}$ angka 84 dengan tingkat signifikansi 0.05 adalah sebesar 2,71. Hasil perhitungan Uji F ini dapat dilihat pada tabel berikut:

Berdasarkan Tabel 12 diatas diperoleh hasil signifikansi $F$ hitung sebesar 7,032 > F Tabel $(2,71)$ dan signifikansi $F$ sebesar $0,000<0,05$. Artinya nilai $\mathrm{F}$ hitung lebih besar dari pada $F$ tabel, dan nilai signifikan lebih kecil dari 0,05. Hasil ini dapat diartikan bahwa kelima variabel independen Advertising (X1), Sales Promotion (X2) Personal Selling (X3), Public Relation (X4) dan Direct Marketing (X5) berpengaruh positif dan signifikan secara simultan terhadap keputusan pembelian sepeda motor merek honda.
Koefisien determinasi $\left(\mathrm{R}^{2}\right)$ dalam output SPSS terletak pada tabel Model Summary $^{b}$ dan tertulis R.square berkisar Nol (0) sampai Satu (1) Berikut tabel yang menunjukkan hasil pengujian determinasi.

Dari hasil diatas menunjukkan bahwa nilai koefisien determinasi yang di sesuaikan ( $R$ Square) sebesar 0,311 atau sebesar $31,1 \%$. Hal ini menunjukkan bahwa keputusan pembelian sepeda motor merek honda dapat dijelaskan oleh bauran komunikasi pemasaran sebesar 31,1\% sedangkan sisanya sebesar $(100 \%-31,1$ $\%)=69,9 \%$ di jelaskan oleh faktor lainnya di luar dari variabel bauran komunikasi pemasaran.

\section{KESIMPULAN DAN SARAN}

Dari hasil analisi deskriptif dapat diambil kesimpulan bahwa faktor public relation, advertising dan sales promotion dan menjadi alasan terkuat mengapa responden mengambil keputusan untuk membeli sepada motor merek honda.

Sedangkan dari hasil uji $\mathrm{t}$ dapat ditarik kesimpulan bahwa variabel public relation dan direct marketing saja yang berpengaruh dan signifikan terhadap keputusan pembelian sepeda motor merek honda. Sedangkan hasil uji $F$ bauran komunikasi pemasaran yang variabelnya advertising, personal selling, sales promotion, public relations dan direct marketing berpengaruh secara simultan terhadap keputusan pembelian sepeda motor merek honda.

Tetap mempertahankan dan menjaga nama baik honda, dan terus beriklan di media elektronik dan media lainnya agar top mind di benak calon konsumen masih menjadi milik honda. Meningkatkan kemampuan tenaga pemasar (marketer) dalam melakukan pendekatan kepada calon konsumen. 


\section{DAFTAR PUSTAKA}

Hurriyati, Ratih (2015). Bauran Pemasaran Dan Loyalitas

Konsumen. Alfabeta, Cv. Bandung.

Fandy, Tjiptono (2015). Starategi Pemasaran. Penerbit Andi. Yogyakrta

Kotler, Philip dalam Drs. Danang Sunyoto, SH, SE, MM, 2014, Dasar-dasar Manajemen Pemasaran, Konsep, Strategi dan Kasus, Edisi Ke Tiga, CAPS

Kotler, Philip dan Gary, Armstrong. 2008.

Prinsip-prinsip Pemasaran.

Jakarta : Erlangga

Sudaryono (2016). Manjemen Pemasaran. Penerbit Andi. Yogyakarta

Sugiono (2009). Statistic Untuk Penelitian. Alfabeta. Bandung

Sunyoto, Danang (2009). Dasar-Dasar Manajemen Pemasaran. Caps. Yogyakarta
Ujang Sumarwan. 2011. Perilaku Konsumen: Teori dan Penerapannya dalam Pemasaran. Bogor: Ghalia Indonesia

V.Wiratna Sujarweni, 2015, Metedologi Penelitian, Yogyakarta, Pustaka Baru Press.

http://www.tribunnews.com/otomotif/2018/ 07/09/sampai-juni-2018-penjualanmotor-nasional-tembus-3-juta-unit

http://triatmono.info/data-penjualan-tahun2012/data-penjualan-motor-tahun2005/ 